\title{
AccumEx - A New SPD Technique for Fabricating Lamellar Materials
}

\author{
G.K. Muralidharan* and B. VerLinden \\ Department of Materials Engineering, KU Leuven, B-3001, Belgium
}

\begin{abstract}
Accumulated extrusion is a novel plane strain compression technique, akin to the process of accumulated roll bonding, designed to produce ultrafine grained lamellar materials. AA1050 CP-Al processed by AccumEx displayed a grain refinement from $17 \mu \mathrm{m}$ to $1.8 \mu \mathrm{m}$ after 2 passes (equivalent strain of 3.2) with an increase in tensile strength of $\approx 70 \%$. A comparative study with the conventional equal channel angular extrusion technique demonstrated that the former displayed a higher fraction of high angle grain boundaries with very similar trend of grain refinement. Up to now, extrusions up to 8 passes have been performed.
\end{abstract}

DOI: 10.12693 /APhysPolA.128.523

PACS: 81.05.Bx, 81.20.Hy, 81.40.Ef, 83.50.Uv

\section{Introduction}

Severe plastic deformation (SPD), ultra-fine grained (UFG) materials and nanolaminates concepts have been investigated worldwide for several decades. Some of the prominent techniques that have been explored in thorough details are: equal channel angular pressing (ECAP/ECAE), high pressure torsion (HPT) and accumulative roll bonding (ARB) [1-4]. The utilization of these SPD techniques has been realized in structural applications, automobile/aircraft applications and $\mathrm{Cu}^{-}$ $\mathrm{Nb}$ like magnetic materials, because of its unique and special mechanical/functional properties [5-8]. Adapting an available industrial process to the production of UFG materials has lots of advantages for continuous production and process integrations but remains always a great challenge. The development of the ARB process, using conventional rolling mills was a significant breakthrough [1]. But, a major inherent limitation of ARB is that the sheets produced are limited in thickness. As a next step, a new technique based on a conventional extrusion process has been explored. It is called "Accumulated Extrusion" (AccumEx), and is based on a similar principle as ARB. In the present work, the new technique has been validated with AA1050 CP aluminium and the microstructural and mechanical properties will be compared with the results from ECAP.

\section{Experiments}

As received, hot rolled and non-recrystallised AA1050 $\mathrm{CP}$ aluminium (with composition as shown in Table I) was used as starting material for the experiments. The experimental setup is a plane strain extrusion with a re-mountable die mouth, made of hardened steel and

\footnotetext{
* corresponding author; e-mail: gokulakrishna.muralidharan@mtm.kuleuven.be
}

TABLE I

Composition of AA 1050 measured by ICP analysis.

\begin{tabular}{c|c|c|c|c|c|c|c|c|c|c}
\hline \hline Elements & $\mathrm{Cu}$ & $\mathrm{Fe}$ & $\mathrm{Mg}$ & $\mathrm{Mn}$ & $\mathrm{Si}$ & $\mathrm{Ti}$ & $\mathrm{Zn}$ & $\mathrm{Ni}$ & $\mathrm{Cr}$ & $\mathrm{Al}$ \\
\hline weight \% & 0.02 & 0.18 & 0.03 & 0.02 & 0.02 & 0.005 & 0.0015 & 0.005 & 0.005 & rest
\end{tabular}

coated with $\mathrm{AlCrN}$. The die angle is $90^{\circ}$ and the lubricant used is $\mathrm{MoS}_{2}$. Four plates/sheets of $50 \mathrm{~mm} \times 20 \mathrm{~mm} \times$ $5 \mathrm{~mm}$ were used as the starting processing material. They were surface treated, stacked and extruded together to a final dimension of $200 \mathrm{~mm} \times 20 \mathrm{~mm} \times 5 \mathrm{~mm}$ (reduced along thickness), which was cut into 4 equal lengths, surface treated and re-extruded up to 8 times. A surface treatment was used to ensure quality bonding between the sheets: surface grinding with 80 -grade $\mathrm{SiC}$ abrasive paper followed by wire-brushing using $0.3 \mathrm{~mm}$ diameter steel wires. The samples were stored in ethanol to guarantee minimum oxidation until processing. The extrusion was done at a rate of $6 \mathrm{~mm} / \mathrm{min}$.

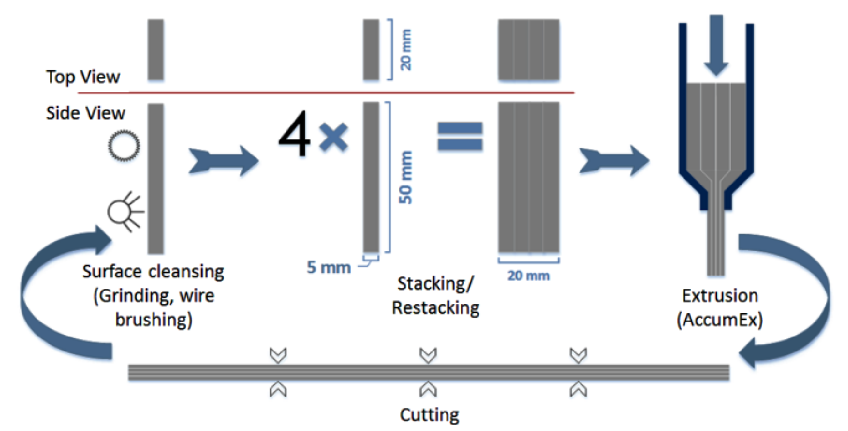

Fig. 1. Schematic representation of the AccumEx process.

Figure 1 shows the schematic representation of the process. The reduction after each extrusion pass is $75 \%$. The equivalent Von-Mises strain, $\varepsilon_{\text {equiv }}=2 / \sqrt{3} n \ln (\mathrm{ER})$ ( $n=$ number of passes; extrusion ratio, $\mathrm{ER}=\frac{A_{0}}{A}$, $A_{0}$ and $A$ are the initial and final area of the crosssection, respectively) is 1.601 after each pass. The number of layers produced after each pass is $4^{n}$ with $n$ being 
the number of passes. The experiments were performed up to 8 passes, which corresponds to an $\varepsilon_{\text {equiv }}$ of 12.81 and 65536 layers with each layer having a thickness of $\approx 79 \mathrm{~nm}$. The scanning electron microscopy (SEM) microstructures/orientation maps were observed along the transverse section using a Nova FEI nanoSEM. TSL data collection software was used for the electron backscattered diffraction (EBSD) measurement. The Keller reagent was used as etchant. The mechanical properties were evaluated using the Vicker microhardness measurements and tensile strength measurements (INSTRON 4467).

\section{Microstructures and orientation maps}

The microstructures of the AccumEx processed AA 1050 samples, obtained by EBSD on the ED-ND sections, are shown in Fig. 2. The process of grain

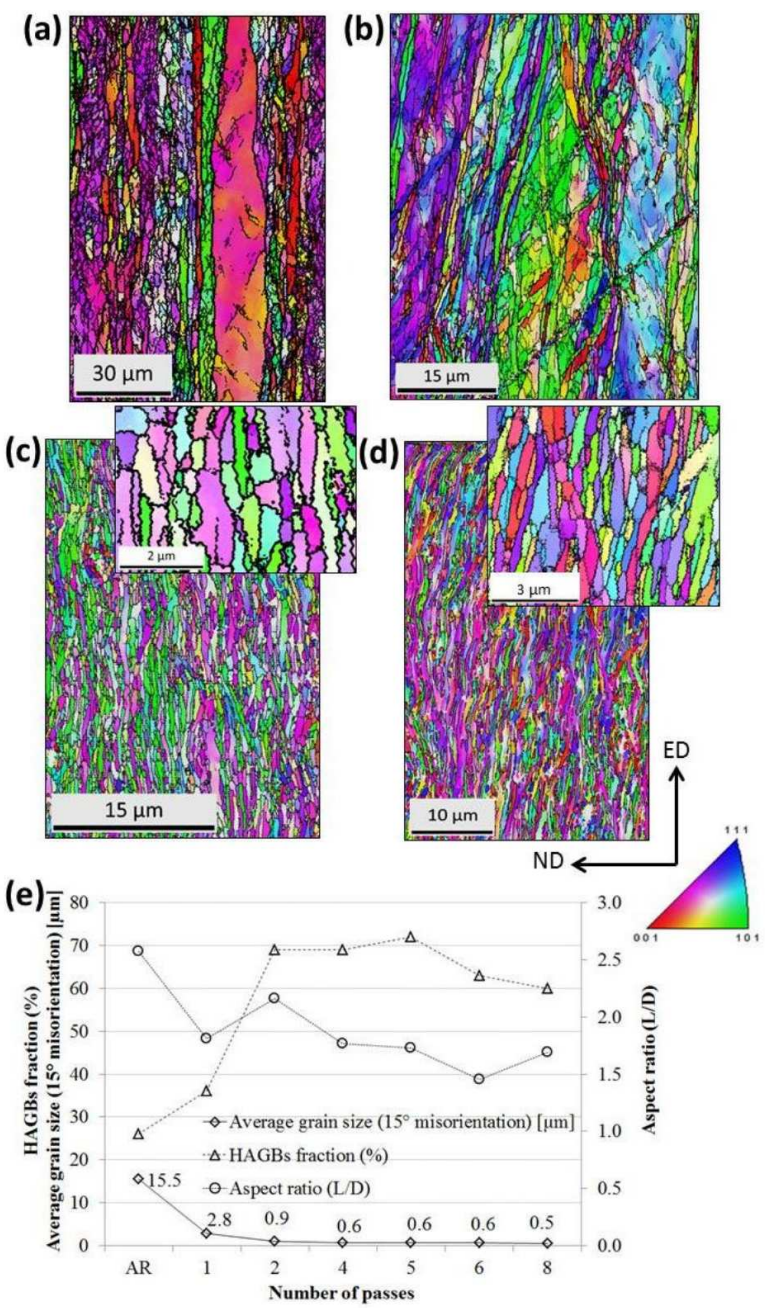

Fig. 2. EBSD maps of the AA 1050 laminates: (a) as received (AR), (b) 1 pass, (c) 4 passes, (d) 8 passes, (e) grain size, HAGBs, aspect ratio distribution with increasing number of passes. The inserts in (c) and (d) are EBSD maps at higher magnification. ED - extrusion direction; ND - normal direction. refinement and the variation in HAGBs fraction are monitored after each pass. The starting material, AA 1050, is a hot rolled sheet with elongated grains. Its average grain size is $\approx 16 \mu \mathrm{m}$ (ED-ND plane) with an aspect ratio of 3.4 (Fig. 2a). The microstructure develops into a lamellar and elongated structure along the extrusion direction. With the thickness of the laminates reducing after each extrusion pass, the width of the lamellar boundaries (LB's) gradually reduces to $<500 \mathrm{~nm}$. Intersecting these LBs, there are transverse boundaries (TB's). The number of TB's increases with increasing number of passes, which is reflected by a decreasing aspect ratio $(L / D)$ of the grains (calculated by manual intercept method in Fig. 2e). The mean equivalent grain size $\left(15^{\circ}\right.$ misorientation boundaries) drastically reduced from $\approx 16 \mu \mathrm{m}$ to $\approx 4.2 \mu \mathrm{m}$ just after 1 pass $\left(\varepsilon_{\text {equiv }}=1.605\right)$ and to $\approx 1.3 \mu \mathrm{m}$ after 2 passes $\left(\varepsilon_{\text {equiv }}=3.21\right)$. The HAGBs fraction increased from $28 \%$ to $\approx 60 \%$ and $\approx 84 \%$ after 1 and 2 passes, respectively (Fig. 2b). The grain refinement after each extrusion pass and their corresponding HAGBs fraction are represented in Fig. 2e. A saturation of the HAGBs fraction can already be noticed after 2 passes (16 layers). After 4 passes (64 layers), the grains along the width of the LB's reduces to $\approx 300-400 \mathrm{~nm}$ and saturate while the length of the LB's is $\approx 1.1 \mu \mathrm{m}$ which continue fragmenting up to 8 passes. Therefore, after 4 passes, the grain refinement is majorly accompanied by reduction of the aspect ratio which is also shown in Fig. 2e. The final equivalent grain size, HAGBs fraction and aspect ratio achieved after 8 passes (65536 layers) of extrusion are $\approx 600 \mathrm{~nm}, 82 \%$ and 2.1 , respectively. Although, the overall microstructure is lamellar, the morphology of the grains, which were straight after 2 passes, experiences bending of around $10-15^{\circ}$ along the extrusion direction at higher strains ( $>4$ passes; Fig. 3 ).
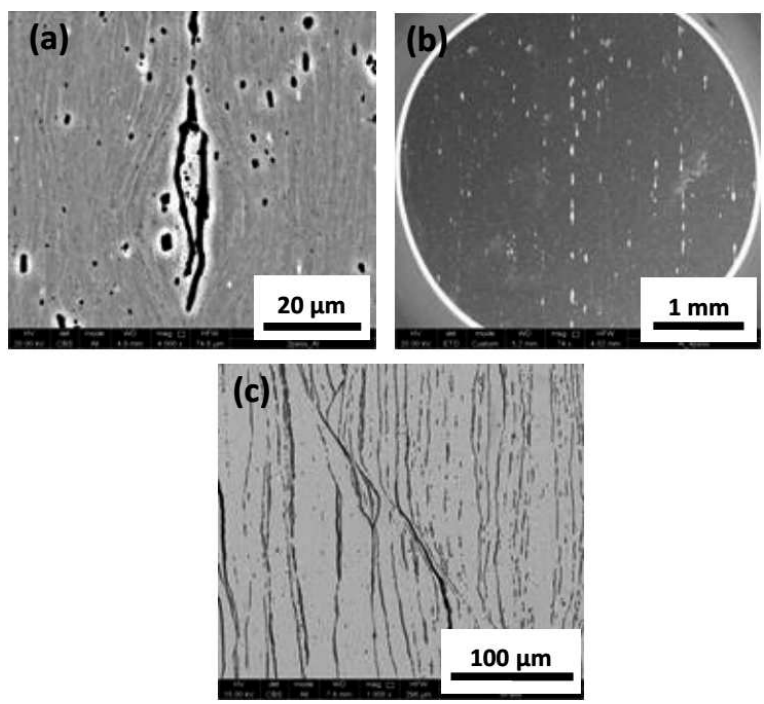

Fig. 3. SEM images of the interfaces: (a) bending of grains at interface regions after 2 passes, (b) straight looking interfaces after 4 passes, (c) bending and shearing of interfaces after 8 passes. 
The reason for such bending is uncertain but presumably trapped $\mathrm{Al}_{2} \mathrm{O}_{3}$ impurities, detected by energy dispersive spectroscopy (EDS) as $\mathrm{Al}$ and $\mathrm{O}_{2}$, at the interfaces are expected to play an influential role in it (as seen in the SEM image of Fig. 3). They can originate from the remnants after wire brushing. At higher strains, bending gets more prominent and is observed as an irregular deformation of the interfaces (Fig. 3c) possibly because of inhomogeneous hardening of the material along the interfaces during the processing.

The evolution of HAGBs can be associated with the increasing mis-orientations between the grains and the dynamic recovery of the grain sub-structures $[9,10]$. In plane strain compression, the deformation has a geometrical reduction along the thickness direction and an elongation along the longitudinal direction. The applied deformation is inhomogeneously accommodated, partially by the elongation of the grains along the ED and by splitting/fragmentation. Microscopic features such as deformation bands, shear bands $\left(35^{\circ}\right.$ from ED in case of pure shear), etc., prominently seen after 1 pass; Fig. 2b, during the deformation process further assist in the development of sub-structures and grain fragmentation $[4,10,11]$. These sub-structures are represented as the low angle grain boundaries (LAGBs, $<15^{\circ}$ misorientation) in the EBSD maps. With increasing strains, these LAGBs gradually transform to high angle grain boundaries (HAGBs, $>15^{\circ}$ mis-orientation). From Fig. $2 \mathrm{~b}-\mathrm{d}$, it can be seen that all the sub-structures developed after 1 pass are transformed to HAGBs at the expense of the LAGBs assisting in development of ultrafine grain structures (UFGs)

\section{Mechanical properties}

The hardness of the AA 1050 after each extrusion pass is presented in Fig. 4a. The measurement was done on the ED-ND sections using a Vickers hardness tester (Zwick 3202) at a load of $300 \mathrm{~g}$ and $10 \mathrm{~s}$ holding time. The starting material had a hardness of $44 \mathrm{HV}_{0.3}$. After 1 pass, there was a drastic increase to $55 \mathrm{HV}_{0.3}$ which further increased linearly and saturated after 4 passes $\left(\varepsilon_{\text {equiv }}=6.42\right)$ at $\approx 68 \mathrm{HV}_{0.3}$. The first increase of $31 \%$ is majorly due to strain hardening but a further linear increase to $68 \mathrm{MPa}$ has also a substantial contribution from the reducing grain size (Hall-Petch effect). As the UFGs are formed, the strain hardening gradually saturates after 4 passes. Tensile tests were performed along ED using an INSTRON 4467 (30 KN load cell) at a strain rate of $10^{-3} / \mathrm{s}$. From the results, shown in Fig. $4 \mathrm{~b}$, the yield strength (YS) steadily increased by $103 \%$ up to 4 passes and maintains almost the same value for the 6 th pass. But there is a drastic reduction in the elongation from $\approx 26 \%$ to $\approx 6 \%$. However, the elongation after 1 and 2 passes has been observed to be exceptionally good compared to the ARB processed materials [12]. The reducing elongation can be attributed to the saturated strain hardening. Likewise, the presence of cracks/pores at the interfaces can also influence it. The yield strength
TABLE II

Comparative evaluation of ECAP and AccumEx at equivalent strain $\approx 9[13]$.

\begin{tabular}{c|c|c|c}
\hline \hline Equivalent strain $\approx 9$ & $\begin{array}{c}\text { Grain } \\
\text { size } \\
{[\mu \mathrm{m}]}\end{array}$ & $\begin{array}{c}\text { HAGBs } \\
\text { fraction } \\
{[\%]}\end{array}$ & $\begin{array}{c}\text { Yield } \\
\text { strength } \\
{[\mathrm{MPa}]}\end{array}$ \\
\hline 8 pass ECAP (route $B_{\mathrm{c}}$ ) & 1.2 & 60 & 200 \\
6 pass AccumEx & 0.64 & 83 & 195
\end{tabular}
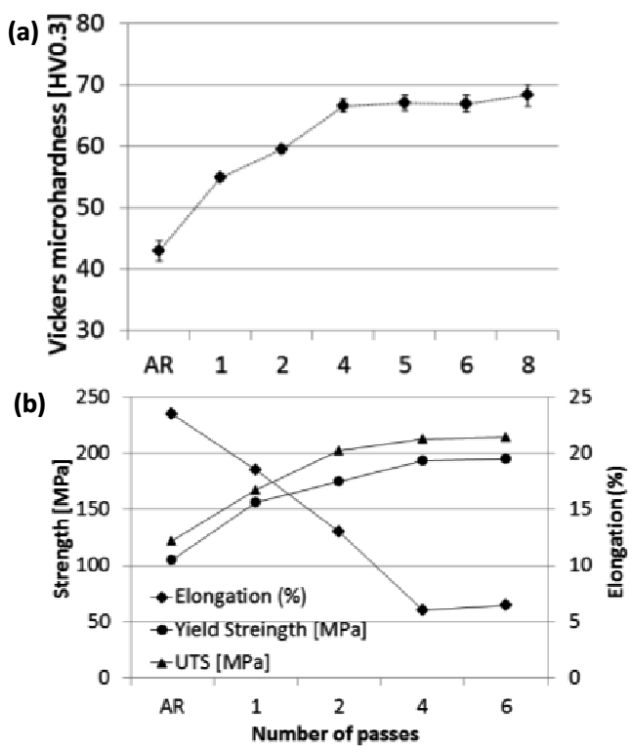

Fig. 4. (a) Hardness evolution and (b) yield strength, ultimate tensile strength (UTS) and elongation data with increasing number of extrusion passes.

after 6 passes is $200 \mathrm{MPa}$ with an elongation of $6.5 \%$, which is the same as that after 4 passes and fracture occurred in the laminates, which reveals the influence of inter-lamellar volume defects. Tensile test results after 7 passes and 8 passes showed very low elongation properties and the premature failure is mainly due to delamination/fracture of the interfaces during the test. Therefore, further investigation is desired to investigate the formation of such cracks/pores during the processing of the samples. No such issues have been reported in literature so far for ARB, but varying properties of the materials from different authors with respect to yield strength and elongation properties can be due to the different degree of bonding and probable presence of volume defects in the samples processed $[12,14]$.

\section{Conclusion}

The validation of the novel SPD technique - AccumEx was demonstrated on AA 1050 aluminium. Compared with their ECAE counterpart, the evolution of UFG and HAGBs structures in AccumEx is rapid. AccumEx was very efficient in achieving UFG structures with HAGBs fraction $>80 \%$ at equivalent strain 6.4. However, the UFGs in ECAP are more equiaxed while they are mainly lamellar for AccumEx. After a ECAP strain 
of $\approx 9.2$ a yield strength of $200 \mathrm{MPa}$ was achieved with $20 \%$ elongation. While in case of AccumEx, the same was achieved after a strain of $\approx 6.5$ but with $6 \%$ elongation.

The properties - grain refinement, hardness and strength after AccumEx are in par with ARB with better elongation properties. Lamellar UFG formed already after 4 passes of AccumEx (strain 6.4) and developed into less lamellar grains with an aspect ratio $\approx 2$ after 8 passes (strain 12.81). Furthermore, after 4 passes a strength increase of $103 \%$ with good elongation properties were achieved. But, materials processed after 4 passes showed poor ductility, probably due to the influence of interface cracks/pores generated during the processing, which desires further investigation. Nevertheless, the novel technique is very promising and possesses a good scope in producing UFG laminate materials.

\section{Acknowledgments}

This research has been funded by the Interuniversity Attraction Poles Programme (P7/21) initiated by the Belgian Science Policy Office.

\section{References}

[1] Y. Saito, H. Utsunomiya, N. Tsuji, T. Sakai, Acto Mater. 47, 579 (1999).

[2] R.Z. Valiev, R.K. Islamgaliev, I.V. Alexandrov, Prog. Mater. Sci. 45, 103 (2000).
[3] R.Z. Valiev, J. Mater. Sci. 42, 1483 (2007).

[4] B. Verlinden, Metalurgija 11, 165 (2005).

[5] R. Valiev, Y. Estrin, Z. Horita, T. Langdon, M. Zechetbauer, Y. Zhu, JOM 58, 33 (2006).

[6] R. Valiev, Nat. Mater. 3, 511 (2004).

[7] R.Z. Valiev, M.J. Zehetbauer, Y. Estrin, H.W. Höppel, Y. Ivanisenko, H. Hahn, G. Wilde, H.J. Roven, X. Sauvage, T.G. Langdon, Adv. Eng. Mater. 9, 527 (2007).

[8] X. Sauvage, G. Wilde, S.V. Divinski, Z. Horita, R.Z. Valiev, Mater. Sci. Eng. A 540, 1 (2012).

[9] F.J. Humphreys, P.B. Prangnell, J.R. Bowen, A. Gholinia, C. Harris, Philos. Trans. A Math. Phys. Eng. Sci. 357, 1663 (1999).

[10] D.A. Hughes, N. Hansen, Acta Mater. 45, 3871 (1997).

[11] V.M. Segal, Mater. Sci. Eng. A 338, 331 (2002).

[12] L. Su, C. Lu, H. Li, G. Deng, K. Tieu, Mater. Sci. Eng. A 614, 148 (2014).

[13] S. Poortmans, B. Verlinden, Mater. Sci. Forum 503-504, 847 (2006).

[14] I. Topic, H.W. Höppel, M. Göken, J. Mater. Sci. 43, 7320 (2008). 